\title{
VIVENCIANDO UMA RELAÇÃO DE AJUDA COM PACIENTE NO PÓS-OPERATÓRIO DE TRANSPLANTE HEPÁTICO*
}

\author{
Eliana Maria Scarelli** \\ Antônia Regina Furegato Rodrigues***
}

\begin{abstract}
RESUMO: A relação de ajuda é, muitas vezes, uma forma própria de trabalho, característica de certos profissionais. O enfermeiro, na sua prática diária, pode estar ajudando o paciente durante a execução de procedimento técnicos de rotina. Ele precisa ter consciência do que está fazendo, avaliar sua atuação com base num referencial humanista e procurar aperfeiçoar-se nesta prática. Este estudo apresenta a análise crítica de uma vivência de interações enfermeiro-paciente (internado em Unidade de Terapia Intensiva após Transplante hepático) segundo o referencial teórico das relaç̋̃es interpessoais. Das 3 interações podemos destacar a importância do nosso posicionamento claro e objetivo, de como lidamos com as ansiedades, da avaliaçào da adequacidade da comunicação e dos benefícios que podemos estar oferecendo à pessoa que necessita de ajuda.
\end{abstract}

ABSTRACT: The goal of this study is to show the experience of a nurse-patient therapeutic relationship in an intensive therapy unity with a hepatic post-transplant patient. It presents still a critic analysis based on the theoric referential of aids relations with a non-directive approach.

UNITERMOS: Relação de Ajuda - Pós-Operatório - Transplante Hepático

\section{INTRODUÇÃO}

Este trabalho foi desenvolvido a partir de um projeto elaboracio ra disciplina "Relacionamento Interpessoal Enfermeiro-Paciente" do curso de PósGraduação em Enfermagem Psiquiátrica. Consideramos nessa experiência, de suma importância, as leituras realizadas, as discussões para compreensão da temática assim como a vivência na prática. Através desta, pudemos constatar o quanto não estamos acostumados a ver cada indivíduo como um ser único e o quanto somos diretivos em nossas ações.

Segundo ROGERS ${ }^{(2)}$, quando se estabelece uma relação de ajuda com enfoque não-diretivo, a atenção não deve ser focalizada sobre o problema da pessoa, mas sobre a pessoa, estimulando assim seu crescimento, desenvolvimento, maturidade, melhorfuncionamento e maior capacidade para enfrentar a vida.

Partindo do pressuposto acima, optamos por escolher um paciente no pós-operatório de transplante hepático internado na L'nidade de Terapia Intensiva, por ser alguém necessitando de ajuda. Sendo este o primeiro transplante do serviço, a equipe estava ansiosa quanto ao sucesso ou insucesso da cinurgia e quanto à questão de vida e morte do ser humano.

Para RUDIO(3), a relação de ajuda surge, às vezes, como forma própria do trabalho, característica de certos profissionais. Observamos que o enfermeiro, durante a sua prática, pode estar ajudando o paciente, mesmo durante a execução de alguns procedimentos

* Trabalho realizado a partir de projeto elaborado na disciplina "Relacionamento Interpessoal Enfermeiro-Paciente" do curso de Pós-Graduação em Enfermagem Psiquiátrica - nível Mestrado - Escola de Enfermagem de Ribeirão Preto - USP. Apresentado como Tema Livre no $44^{\circ}$ Congresso Brasileiro de Enfermagem. Brasilia, DF, 4 a 9 de outubro de 1992.

** Professor Auxiliar do Curso de Enf ermagem - FMTM - Uberaba.

*** Professor Assistente Doutor do Departamento de Enfermagem Psiquiátrica e Ciências Humanas da Escola de Enfermagem de Ribeirão Preto - USP. 
técnicos. É preciso, pois, que ele tenha consciência do que está fazendo, avalie sua atuação e busque melhorar sempre seu desempenho.

RODRIGUES ${ }^{(1)}$ coloca que na relação de ajuda, o enfermeiro utiliza-se de seus conhecimentos gerais de enfermagem, seus conhecimentos específicos da situação em questão, dos procedimentos técnicos assim como de si próprio como instrumento terapêutico. Nesses contatos de pessoa-a-pessoa deve agir de maneira sistematizada e empática frente a cada pessoa em crise.

Para TRAVELBEE(4) a relação de ajuda possui um caráter terapêutico muito importante, quando o enfermeiro usa sua própria pessoa como instrumento para ajudar pessoas, famílias ou comunidade a resolver seus problemas.

Agir de forma sistematizada implica em ter clareza do que se que realizar, ter os conhecimentos teóricos que explicam ou dão suporte às propostas, $\mathrm{e}$ agir segundo esses referencial, buscando atingir o objetivo proposto.

No caso do enfermeiro que quer ajudar as pessoas a resolverem os seus (delas) problemas, é fundamental que o profissional esteja apoiado numa teoria que lhe permita olhar o paciente como um ser humano único que está enfrentando alguma dificuldade, precisando de ajuda, e que o enfermeiro poderá auxiliá-lo no caminho da resolução de seus problemas, sem impor qualquer direção pessoal. Muitos estudos, especialmente realizados por ROGERS ${ }^{(2)}$ e na enf ermagem por TRAVELBEE(4), oferecem material substancial pra quem deseja humanizar a assistência de enfermagem.

O presente estudo tem como objetivo apresentar a análise crítica de uma vivência de interações enfermeiro-paciente (pós-operatório de transplante hepático na UTI), segundo o referencial das relações interpessoais.

\section{METODOLOGIA}

Foram realizadas 3 interrelações, no tempo de 20 a 30 minutos, cada uma. O paciente estava internado em uma Unidade de Terapia Intensiva do Hospital das Clínicas de Campinas - UNICAMP.

Foi utilizada a entrevista não-diretiva e, imedia- tamente após, as interrelações foram analisadas com base no referencial das relações interpessoais.

Selecionamos alguns trechos que consideramos mais importantes nas interações.

\section{APRESENTAÇÃO DO CASO}

Paciente A.B.O. 34 anos, casado, alcóolatra, portador de Cirrose Hepática. Apresentou várias internações (dentro de um ano) e a solução seria um transplante hepático (transplante realizado dia 15/09/91).

A necessidade de interagirmos com ele surgiu por ser o primeiro transplante hepático que estava sendo realizado naquele serviço. $O$ paciente estava muito ansioso com relação aos resultados da cinurgia.

\section{Interações Enfermeiro-Paciente e Comentários}

\section{$1^{a}$ Interação}

E* - Bom dia A.

A $^{* *}$ - Bom dia.

E - Gostaria de estar conversando um pouco com você e se você quiser falar a respeito de alguma coisa estou aqui para ouvi-lo. Meu nome é E., sou enfermeira aqui da UTI e já ajudei a cuidar algumas vezes de você.

A - É, é bom conversar.

É importante, no primeiro encontro, estabelecer o que se pretende com a interação. Caso contrário, o paciente não vai saber o que fazemos ali. Para ele, pode parecer uma conversa normal e não chegar ao alcance de objetivos.

E - E como você tem passado?

A - Acho que estou um pouco melhor, mas um pouco cansado já.

E - Cansado?

A - É que já estou há vários dias aqui, e mesmo antes de fazer o transplante, estive internado. Fui de alta para casa de manhã e, à tarde, mandaram avisar que havia aparecido um doador e que se tudo desse certo, iria ser submetido ao transplante.

E - O transplante foi realizado no mesmo dia?
* Enfermeiro

** Paciente 
A - Foi, tinha outra pessoa para receber o figado. Fiquei muito angustiado e ccฑ medo que não desse certo.

E - Você estava com medo?

A - Medo de que não desse nada certo, de não poder ver mais minha filha.

\section{E - De não poder ver sua filha?}

Nesse momento, entrou um médico no quarto e começou a falar com o paciente.

Quando o paciente colocou que estava com medo, entendemos que era medo da "morte". Foi só retomar um pouco do que ele dissera e logo abordou 0 que estava deixando-o angustiado.

O relacionamento ficou prejudicado quando entrou uma pessoa no quarto (médico). Tentei retomar, mas o paciente disse que queria dormir. Marcamos 0 próximo encontro, ele solicitou que fosse à tarde por sermai s tranquililo. Maramos o horário... é importante no relacionamento terapêutico que se estabeleça um compromisso quanto a dia e horário.

\section{2a Interaçăo}

Quando chequei no horário que combinamos, ele estava fora do quarto. Estava sentado numa cadeira.

A - Me tiraram do quarto, eu năo agulentava mais a cama, só que o corte dói muito...

L - No começo é assim, é uma cirurgia grande e por estar sentado vai doer mesmo.

Houve um silêncio. Fui diretiva e acabei respondendo o que o paciente não queria ouvir, esquecendome que cada indivíduo é um indivíduo. Muitas vezes, nós enfermeiros, devido à nossa formação, achamos que com isto acalmamos o paciente, mas o que constatamos, na prática (vivência) é o contrário...

Para retomar tive que lançar uma outra pergunta. No decorrer da interação, o paciente colocou que o médico disse que logo ele iria para a enfermaria. Falou também que estava sentindo-se melhor do que no dia em que fui falar com ele ( $1^{\circ}$ encontro) e que agora, estava podendo comer de tudo.

Marcamos a $3^{\mathbf{a}}$ interação e ele lembrou-me da possibilidade de estar na enfermaria. Afimou que gostaria que eu fosse até lá falar com ele.

\section{3* Interaçăo}

O paciente estava na enfermaria. Fui até lá como combinamos.
E - Como está passando?

A - Vai indo, agora um pouco melhor. Pelo menos aqui consigo ver o dia e também sempre tem ficado alguém da minha familia aqui.

E - Eles têm ficado?

A - À noite, fica minha esposa e, durante o dia, minha mãe, minhas irmãs. Aqui estou andando, sento um pouco no sol...

E - Quando?

A - Não consigo andar muito, mas ando no corredor. Acabo ficando cansado e volto para cama.

E - Cansado...

A - Um pouco de falta de ar e também desanimado. Nãoagulento mais hospital, queria estar em casa. Aqui tem muita gente.

E - Muita gente?

A - Muitos médicos, enfermeiros e ainda tem vindo uma moça (psicóloga) falar comigo. Quando ela vem, não falo nada. Ela fica só perguntando da minha vida, da minha casa.

E - Você não fala quando ela vem aqui?

A - Falo pouco, não gostei do monte de perguntas que ela faz.

Quando o paciente refere-se à psicóloga, de quem ele não gosta porque ela vem fazer-lhe uma série de perguntas sobre sua vida, nos faz refletir sobre a atuação do enfermeiro (Ficou em silêncio).

Consideramos que o enfermeiro tem condiçð̃es de estar realizando relacionamento terapêutico na sua prática com seus pacientes. A pessoa que vem de fora (psicólogo) não está tão próxima do paciente quanto o enfermeiro. É necessário conhecimento específico, que nós temos por formação, principalmente para 0 enfermeiro de terapia intensiva. No entanto, o enfermeiro passa a maior parte de seu tempo preocupado quanto aos aparelhos, técnicas, inúmeros procedimentos e deixa de lado o indivíduo como pessoa. Estando este paciente enfrentando uma situação crítica, na maioria das vezes, uma simples atenção poderia ser de alto valor terapêutico.

No final desse contato o paciente disse:

A - É, o médico falou que talvez eu vá embora na $2^{\mathrm{a}}$ feira.

E - Na $2^{\mathrm{a}}$ feira?

A - É, depois venho ao ambulatório.

E - Se você quiser, verifique o dia do retomo e 
poderemos marcar para conversarmos.

A - Amanhā você vem?

E - Não, estou de folga, hoje também já tenho que ir. Estou de plantão.

A - Passe aqui na $2^{\mathrm{a}}$ feira e, se eu já fui de alta, deixo marcado o dia do ambulatório para você.

E - Tudo bem, passo na $2^{\mathrm{a}}$ feira, bom domingo.

A - Obrigado.

\section{CONSIDERAÇÕES FINAIS}

É muito importante desde o início do contato com o paciente, que se estabeleça dia, tempo, finalidade da nossa atuação, senão acaba ficando um relacionamento social e não terapêutico.

Nestas interrelações, é possível perceber nitidamente que, sempre que $\mathbf{E}$ permitiu que $\mathbf{A}$ falasse sobre suas preocupaçð̃es, que ela o mantinha dentro do tema do seu interesse, a relação tinha uma fluidez positiva.

Quando havia cortes, vinha silêncio, mudava o assunto, o paciente manifestava outros desejos, evidenciando a inadequação da conduta do enferneiro.

Interessante é notar que $\mathbf{A}$ referiu inritação frente a um interrogatório que lhe era desagradável, e a demonstração de sua disponibilidade frente a uma interação onde ele era o centro.

Durante a interação, quando havia silêncio, surgiram dificuldades por parte do enfermeiro (E). Não aguentando a ansiedade dessa situação, procurava fazer outra pergunta, mudando até de assunto, em vez de permanecer em silêncio e deixar que o paciente se manifestasse.

Encontramos enfermeiros que dizem não ter tempo para estar conversando com o paciente. Isto é muito comum no caso dos enfermeiros de terapia intensiva, pois alegam que tudo é muito corrido, muitos procedimentos técnicos a fazer. Entretanto, na maioria das vezes, basta ouvir o que o paciente tem a dizer e estaremos ajudando-o.

A oportunidade de vivenciar um relacionamento interpessoal enfermeiro/paciente foi muito positiva, visto que é na prática o que podemos perceber o quanto agimos errado (de forma diretiva). Ficou também claro que a relação terapêutica pode ocorrer a qualquer momento, desde que estejamos em contato com o paciente e com o propósito de agir terapeuticamente.

\section{REFERÊNCIAS BIBLIOGRÁFICAS}

1. RODRIGUES, A.R.F. Enfermagem de Saude Mental para mulheres em crise acidental. Ribeirão Preto, 1986, Tese (Doutorado) Universidade de São Paulo - EERP e EEUSP, 140p.

2. ROGERS, C.L. Tornar-se pessoa. São Paulo: Martins Fontes, 1982, 360p.

3. RUDIO, F.V. Orientação não diretiva na educação, no aconselhamento e na psicoterapia. Petrópolis: Vozes, 10 ed, 1990, 109p.
4. TRAVELBEE, J. Intervención en enfermeria psiquiatrica: processo de la relación de persona. Colombia: Carvajal S.A., 1982, 282p.

Recebido para publicação em 30.9 .93 